\title{
BRASÍLIA IMAGINADA: a cidade representada por meio dos seus processos simbólicos
}

Daniela Fávaro Garrossini é Professora da Universidade de Brasília, no Instituto de Artes, Departamento de Design, Coordenadora da Pós-graduação em Design da Universidade de Brasília, Doutora em Comunicação pela mesma universidade. Fez seu pós-doutoramento no Centro de Estudos Superiores de Comunicación para América Latina (CIESPAL) (20152016). Participa do grupo de pesquisa Compolíticas, do Grupo de Trabalho em Tecnopolítica FLACSO, da Rede Internacional Tecnopolítica: Redes, Poder e Ação Coletiva. É professora visitante na Universidade de Sevilla (Espanha), Representante do Brasil da Vocal de comunicação da União Latina de Economia Política da Informação, da Comunicação e da Cultura (ULEPICC FEDERAL). É diretora da Revista Redes.Com. $<$ daniela.garrossini@gmail.com > ORCID: 0000-0003-4031-4840
Resumo Pretende-se no estudo que se apresenta, a partir da metodologia criada por Armando Silva (2006) para a composição simbólica das "Cidades Imaginadas", investigar as semelhanças e diferenças entre a cidade midiatizada e a cidade vivida e percebida por seus moradores. A pesquisa tem enfoque no espaço urbano desde uma perspectiva do cidadão, onde o imaginário se impõe a princípio como um conjunto de imagens e signos, de objetos do pensamento e vida cotidiana, cujo alcance e coerência podem variar e cujos limites de redefinem sem cessar. Partimos deste ponto de vista por compreender que é imprescindível começar a pensar sobre a lógica da comunicação, a cidade e a cidadania a partir de outros parâmetros que não o paradigma distributivo e eficiente ou abordagens tradicionais, definindo uma agenda e linhas de desenvolvimento de pesquisa e intervenção social baseadas na linguagem de seus cidadãos e na demanda pelo comum.

Palavras chave Cidades Imaginadas, Memória, Cultura, Processos Participativos. 


\section{BRASÍLIA IMAGINED: the city represented through its symbolic processes}

Fátima Aparecida dos Santos é Graduada em Design (programação visual) pela UNESP- Bauru em 1997, Mestre em Comunicação e Semiótica pelo PPG-COS da PUC_SP, Doutora em Comunicação e Semiótica pelo PPGCOS da PUC_SP. Estágio Pós Doc na Università Degli Studi di Torino - Depto Filosofia da Educação/ CIRCE - Semiótica (2016/2017). Professora Associada do Departamento de Design(UnB). Atua no curso de graduação de Design, no Programa de Pós-Graduação em Arte e no Programa de Pós-Graduação em Design da UnB. Vice-Coordenadora do GT Semiótica da Comunicação na Sociedade Brasileira de Ciências da Comunicação. Diretora do Instituto de Arte - UnB 2018 - 2022

<designerfatima2012@gmail.com> ORCID: 0000-0003-1009-8235

Beatriz Melo Franco Nery é Graduada em Design (programação visual) pela Universidade de Brasília, Mestranda em Design pela mesma universidade. Participa do grupo de pesquisa LabUrb Design$\mathrm{UnB}$ e desenvolve suas pesquisas desde 2016 no tema Imaginários Urbanos. <beatrizmfnery@gmail.com> ORCID: 0000-0002-0486-8267
Abstract It is intended in the present study, stemming from the methodology created by Armando Silva (2006) for the symbolic composition of "Cities Imagined", to investigate the similarities and differences between the city portrayed in media and the city as it is lived and perceived by its residents. The research is focused on urban space from the citizen's perspective, where the imaginary is imposed, at first, as a set of images and signs, of thought objects and everyday life, whose reach and coherence may vary and whose limits do not cease to be redefined. We begin from this point of view for understanding it is essential to think about the logics of communication, city and citizenship using parameters other than the distributive and efficient paradigm or traditional approaches, and so define an agenda and lines of research development and social intervention based on the language of its citizens and the demand for the common.

Keywords Cities Imagined, Memory, Culture, Participative Processes.

BRASILIA IMAGINADA: la ciudad representada a través de sus procesos simbólicos

Resumen Se pretende en el presente estudio, a partir de la metodología creada por Armando Silva (2006) para la composición simbólica de "Ciudades imaginadas", investigar las similitudes y diferencias entre la ciudad mediatizada y la ciudad vivida y percibida por su población. La investigación se centra en el espacio urbano desde la perspectiva del ciudadano, donde el imaginario se impone en un primer momento como un conjunto de imágenes y signos, objetos de pensamiento $y$ de la vida cotidiana, cuyo alcance y coherencia pueden variar y cuyos límites se redefinen sin cesar. Partimos de este punto de vista entendiendo que es fundamental empezar a pensar en la lógica de la comunicación, la ciudad y la ciudadanía desde otros parámetros que el paradigma distributivo y eficiente o los enfoques tradicionales, definiendo una agenda y líneas de investigación y intervención social para el desarrollo, basada en el lenguaje de sus ciudadanos y la demanda de lo común.

Palabras clave Ciudades imaginadas, Memoria, Cultura, Procesos participativos. 


\section{Introdução}

As cidades são, por excelência, os lugares nos quais as trocas culturais podem ser observadas com maior vigor, sua geografia, e lógica de organização são variáveis e inextricáveis. Para Lefebvre (2012, p.24) 0 tecido urbano pode ser descrito mediante a utilização do conceito de ecossistema, unidade coerente constituída em torno de uma ou várias cidades, antigas ou recentes. Salienta ainda que a cidade é o suporte de uma forma de vida. Já Agamben (2015, p.13) define forma-de-vida ou Bios como uma vida que jamais pode ser separada de sua forma, uma vida na qual jamais é possível isolar alguma coisa como uma vida nua Zoé. Logo na contemporaneidade a vida humana como conhecemos na Terra é a vida na cidade, e esta por sua vez está atrelado de alguma forma com o urbano, ou seja, um ambiente conformado pela tecnologia e pela técnica (SANTOS, 1985). A cidade é também o lugar das conexões entre grupos evidenciadas pelos processos comunicativos e pela emergência dos signos novos. Tais aspectos de criação, uso e troca de informação no ambiente urbano são objeto de estudo da Semiótica da Cultura (LOTMAN, 1996) e, por meio dela, é possível analisar as relações estabelecidas entre os componentes de uma ecologia urbana. Desta forma, compreende-se que a cidade é o espaço qualificado a partir dos seus usos, das suas sintaxes culturais e do modo como essas representam seus habitantes para tais estudos.

A cidade de Brasília ocupa, de certo modo, o imaginário de todos os brasileiros e estrangeiros, primeiro como a 'capital da esperança', 'a cidade modernista' e atualmente pela midiatização do cotidiano político que envolve o poder federal e a exposição constante da cidade em noticiário nacional acaba por induzir ao erro de que tais notícias traduzem de fato o que é a cidade de Brasília e o Distrito Federal. Entretanto a cidade construída, vivida e imaginada por seus habitantes é maior e mais expressiva do que a noticiada ou que a perspectiva histórica. Assim, pretendemos, a partir da metodologia criada por Armando Silva (2006) para a composição simbólica das "Cidades Imaginadas", investigar as semelhanças e diferenças entre a cidade midiatizada e a cidade vivida e percebida por seus moradores. A pesquisa tem enfoque no urbano desde uma perspectiva do cidadão. 0 imaginário se impõe a princípio como um conjunto de imagens e signos, de objetos do pensamento, cujo alcance, coerência e eficácia podem variar e cujos limites de redefinem sem cessar. Para tratar de definir os termos nos referimos a três acepções dos imaginários, os associados a pregnância simbólica da linguagem, os imaginários como inscrição psíquica e em uma perspectiva de uma lógica inconsistente, o imaginário enquanto construção social da realidade.

Partimos deste ponto de vista por compreender que é imprescindível começar a pensar sobre a lógica da comunicação, a cidade e a cidadania a partir de outros parâmetros que não o paradigma distributivo e eficiente ou abordagens tradicionais, definindo uma agenda e linhas de desenvolvi- 
mento de pesquisa e intervenção social baseadas na linguagem de seus cidadãos e na demanda pelo comum. Portanto, o projeto Brasília Imaginada, considera como ponto central e imprescindível, a partir do conhecimento crítico-reflexivo dos vários problemas históricos, tecnológicos, cognitivos, ideológicos e culturais que ocorrem no atual processo de globalização e configuração das cidades, a interface de análise, a partir da visão de seus cidadãos relacionadas aos seus imaginários, desejos e modos de vida.

Ressaltamos que as primeiras ideias em relação a Brasília Imaginada vêm sendo formulada desde novembro de 2017, onde o Programa de Pós-graduação em Design contou com a participação do Dr. Armando Silva e iniciamos a organização de uma primeira oficina para pensar a construção deste projeto que comunicamos neste artigo.

\section{Escolhas metodológicas: os imaginários e suas acepções}

Iniciamos a pesquisa sobre Brasília Imaginada a partir de duas aplicações realizadas no ano de 2018 para testes sobre as possibilidades metodológicas e para traçar perspectivas possíveis de desenvolvimento de novas formas de se construir estudos sobre o desenvolvimento do espaço urbano que considere, para além dos dados oficiais, a perspectiva cidadã. Os imaginários determinam modos de ser e de se comportar, assim como os modos de usar os objetos que eles representam. Nessa medida, os imaginários não existem em um espaço geográfico, mas sim em um espaço simbólico, o que nos permite acompanhar e examinar posições e relações intersubjetivas e ecológicas. Ao mesmo tempo, os objetos que incorporam imaginários estão construindo arquivos que, além de armazenar coisas tangíveis, armazenam experiências estéticas e avaliações simbólicas. Esses arquivos servem para hierarquizar e valorizar culturalmente os objetos e seus imaginários. Nesse sentido, enquanto o imaginário alude à percepção grupal por meio dos desejos, o arquivo implica sua documentação, armazenamento e reconhecimento. Os imaginários apontam para uma categoria cognitiva que revela como os seres sociais, não através da razão, mas através da sensação percebem seus próprios mundos e realidades (Silva, 2012).

Segundo Armando Silva, os imaginários não são apenas representações abstratas e mentais, mas "corporificam" ou "incorporam" em objetos cidadãos que encontramos na luz pública e da qual podemos deduzir sentimentos sociais como medo, amor, a ilusão ou a raiva. Esses sentimentos são arquiváveis sob a forma de escritos, imagens, sons, produções artísticas ou textos de qualquer outra matéria em que o imaginário impõe seu valor dominante ao próprio objeto. Assim, todo objeto urbano não apenas tem sua função de utilidade, mas pode receber uma avaliação imaginária que lhe dá outra substância representacional (Silva, 2009). 
Frente à multiplicação desbordante de experiências e novos processos de mediação propiciados pela necessidade de reposicionamento e transformação das cidades, que demandam novas teorias e ferramentas metodológicas de exploração capazes de atualizarem o conhecimento e saberes de distintos campos científicos sobre as novas realidades de reterritorialização e desenvolvimento da cultura local, o projeto Brasília Imaginada trata, neste sentido, de aportar novas estratégias e desenhos de investigação que lancem luz sobre as formas de comunicação e cultura democrática local, desde matrizes pluridisciplinares de estudos e novos olhares transversais sobre as novas formas de vida e representação das populações no espaço urbano.

Para a organização metodológica, concebemos alguns indicadores de caminhos possíveis para descrever o imaginário urbano, utilizamos as três acepções de Armando Silva (2004): os associados à pregnância simbólica da linguagem (eu), os imaginários como inscrição psíquica (o outro) e o imaginário enquanto construção social da realidade (a estrutura). Nessas três acepções temos diferentes imaginários criados por cada indivíduo e a unidade dessa percepção que demonstra o imaginário coletivo. Além das três acepções, para nós, de fundamental importância, considerou-se ainda as características estruturais de Kevin Lynch (1995), somamos mais cinco conceitos de análise urbana, sendo esses: a) Legibilidade: a legibilidade consiste na capacidade do indivíduo de perceber os ambientes na escala urbana de dimensão, tempo e complexidade através de seus estímulos político-estéticos; b) Construção da imagem: a imagem urbana, segundo Lynch, constitui uma base de importância única para o desenvolvimento individual. A partir da legibilidade do espaço reconhece-se padrões que trazem conforto e acolhimento ao serem percebidos em outros ambientes. Com isso, o indivíduo constrói uma imagem única da cidade; c) Identidade: a identidade é formada pelo imaginário a partir da compreensão individual do espaço. Cria-se uma ideia do que identifica aquilo, de quem são as pessoas que frequentam aquele espaço, do que aquele ambiente significa dentro do grande espectro do imaginário urbano; d) Imaginabilidade: imaginabilidade é a característica (ou o conjunto delas) que confere ao espaço a alta probabilidade de evocar no indivíduo uma imagem forte; e, por fim, e) Estrutura: a imagem da cidade é formada pela estrutura percebida através da legibilidade. A estrutura da cidade ainda se divide em cinco aspectos:

Vias: as vias são ruas, alamedas, avenidas e outros caminhos que cortam o espaço urbano.

Marcos: os marcos são intervenções percebidas pelo indivíduo que marcam e o fazem reconhecer os caminhos que percorrem pela cidade.

Limites: os limites são diferenças político-estéticas percebidas pelo indivíduo que o fazem compreender onde certos espaços urbanos (os bairros) começam e terminam. 
Pontos nodais: os pontos nodais ancoram os espaços, sendo locais onde o indivíduo faz uma parada para pensar de onde se vem e para onde se vai.

Bairros: os bairros são cortados pelas vias, definidos pelos limites, ancorados pelos pontos nodais e salpicados de marcos.

Partindo de uma pesquisa realizada anteriormente e a partir de entrevistas e interpretações dos dados coletados, foi percebida grande discrepância nos espaços da cidade de Brasília, que aparentam representar para seus cidadãos dois extremos de um mesmo espectro. Iniciamos uma experiência prévia em 2018, onde coletamos diversos dados e constituindo as primeiras experiências em relação à Brasília Imaginada. Em um estudo prévio com a participação de alunos de graduação e pós-graduação da UnB, coletamos por meio de entrevistas, diversos dados que tivessem a representação de algumas percepções sensíveis.

A priori foi feita uma pesquisa sobre as características que cidadãos de Brasília, entende-se Brasília não só pelo Plano Piloto mas também as chamadas cidades-satélite ou R.A, Regiões Administrativas, atribuíram a cidade. A entrevista consistia numa série de perguntas que busca na memória do entrevistado(a) as emoções e imagens do mesmo sobre o meio em que ele vive, características através de dicotomias como, por exemplo: lugar mais triste e o mais feliz, o lugar com mais mulheres e mais homens e etc. $O$ entrevistado, a partir dessa entrevista pôde traçar um imaginário próprio sobre a cidade e, assim algumas características pontuais e comuns foram observadas.

A continuidade do estudo buscou um aprofundamento sobre o imaginário urbano com foco nas dicotomias encontradas da cidade. Para isso a pesquisa abrangeu e verificou a importância dos três pilares que compõem a ideia de imaginário coletivo: o eu, o outro e a estrutura; além das relações que existem entre esses três atores. Distanciando o estudo de dados puramente quantitativos na tentativa de captar o conhecimento simbólico das pessoas que habitam e vivem a cidade. Interpretando a cidade como objeto simbólico e coletivo, é essencial analisar as representações de códigos e palavras como expressão simbólica do imaginário urbano. As representações, quando coletivas, simbolizam as percepções territoriais e os sistemas de identificação social presentes no local.

Assim, entende-se a importância da identidade individual dos participantes para entender a sua relação consigo mesmo no espaço e com os outros, fundamentando assim seu imaginário. Dessa forma, a percepção de identidade se torna, nesse estudo, o ponto de partida para compreensão do imaginário coletivo. Tentando entender como as pessoas da cidade se identificam e como identificam as pessoas que a cercam e como ambas estão contidas no espaço, como esse espaço está sendo refletido pelas pessoas. 
Percebe-se também essas dicotomias presentes na cidade como algo não binário e que está em constante mudança e adaptação. Apesar de Brasília ter sido uma cidade planejada e ter boa parte das funções de seus espaços já estipuladas, desde a sua ocupação a cidade sofre um processo urbano natural de mutação e de novas apropriações dos espaços, criando novas relações de affordances. Nesse contexto, isso gera uma forte influência no entendimento da cidade como território, além de particularidades na própria afinidade das pessoas com o espaço na ideia de pertencimento.

Para tal, foi selecionado o espaço amostral da área em torno da rodoviária enquadrando o CONIC e o Shopping Conjunto Nacional como exemplos desses territórios dicotômicos para representar alguns indicativos percebidos na primeira pesquisa de campo. Apesar desses dois espaços serem tão próximos fisicamente e terem sido projetados para funcionar juntos, hoje nota-se uma grande diferença no uso e na percepção de ambos. Também foi possível notar isso com o primeiro estágio da pesquisa, os dois espaços foram bastante citados, nem sempre como análogos, porém remetendo a perfis distintos da cidade. Um relacionado ao limpo, à segurança, ao comércio, restaurantes e outro relacionado ao sujo, aos LGBTs, aos jovens, ao perigo e ao nojo. Mesmo assim, talvez pela localização e proximidade com a rodoviária, centro da capital, os dois apresentaram percepções comuns como o movimento constante de pessoas de todos os lugares.

Em suma, era desejado unir esses fatores para gerar uma amostra de qual seria o imaginário urbano de Brasília e como ele é construído. Entendendo como as pessoas se percebem, percebem o outro e onde isso está localizado no espaço que elas residem e vivem seu cotidiano; onde ela localiza as características próprias no espaço. Assim, compreendíamos possível relacionar essa rede de variáveis para análise da imagem e entendimento do simbólico, e por fim, criar uma narrativa das pessoas que frequentam esses lugares.

A aplicação iniciou-se no espaço da plataforma superior na rodoviário do Plano Piloto, centro da capital, espaço que compreendem a passagem entre os dois edifícios Conic e Conjunto Nacional e os resultados sobre a dicotomia foram significativos sobre o imaginário da cidade. Corroborando com as pesquisas iniciais, das quais tínhamos aproximadamente 1.100 respostas sobre a cidade e seus espaços, os resultados se mostram claros e bastante significativos. $\mathrm{Na}$ etapa de construção do Mapa sobre o Conic e o Conjunto Nacional classificamos 980 respostas (Figura1 e Figura 2), de forma mais aprofundada, conseguimos concluir e validar algumas informações coletadas nas primeiras entrevistas que apresentamos de forma resumida. 
BRASÍLIA IMAGINADA: a cidade representada por meio dos seus

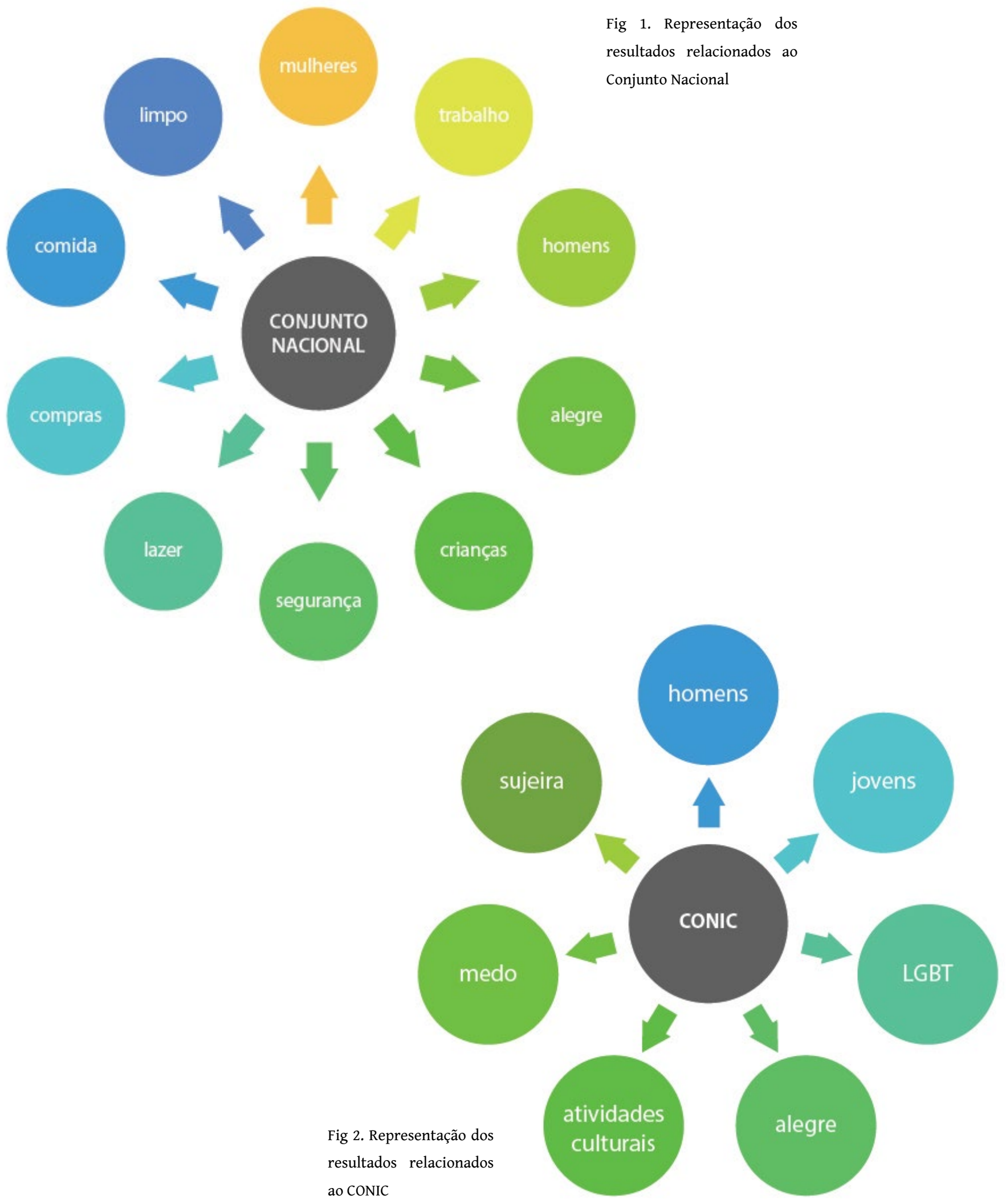

DATJournal v.5 ก.3 2020 
A dicotomia surgiu a partir de um pressuposto de que há contrastes de ordem social e cultural que são atribuídos ao Conic e Conjunto Nacional, os contrastes identificados pelo imaginário coletivo traz possibilidades e ideias de representação, citamos, por exemplo, o conceito lazer vs atividades culturais, onde os entrevistados e participantes por identificar as relações sobre o significado de lazer e de atividades culturais constroem um entendimento de que o lazer é o lugar da compra, do consumo e da segurança, referências diretas ao Conjunto Nacional. Já o Conic é relacionado às atividades culturais, mas também à frequência LGBT e ao medo. Os dois lugares apresentam diversas outras características que detalharemos em outros estudos.

O que se faz importante ressaltar em estudos deste tipo, para além dos estudos quantitativos, é o aprofundamento na construção simbólica dos espaços em questão. O Conjunto Nacional e o CONIC são edifícios espelhados, localizados a partir da mesma distância do centro da cidade, o que em uma descrição estrutural da cidade sugeriria similaridade no uso e frequência. As diferenças são construídas e compreendidas por nós não exatamente por explicações do plano que imaginou-se para Brasília, mas pela memória e vida construída pelas pessoas que aqui habitam. Não nos cabe o julgamento sobre as verdades ou inverdades sobre os dois lugares, o que nos interessa e é apresentado neste fragmento de estudo é a possibilidade de perceber o que é construído a partir dos imaginários e com as informações considerar possíveis reflexões sobre o espaço urbano.
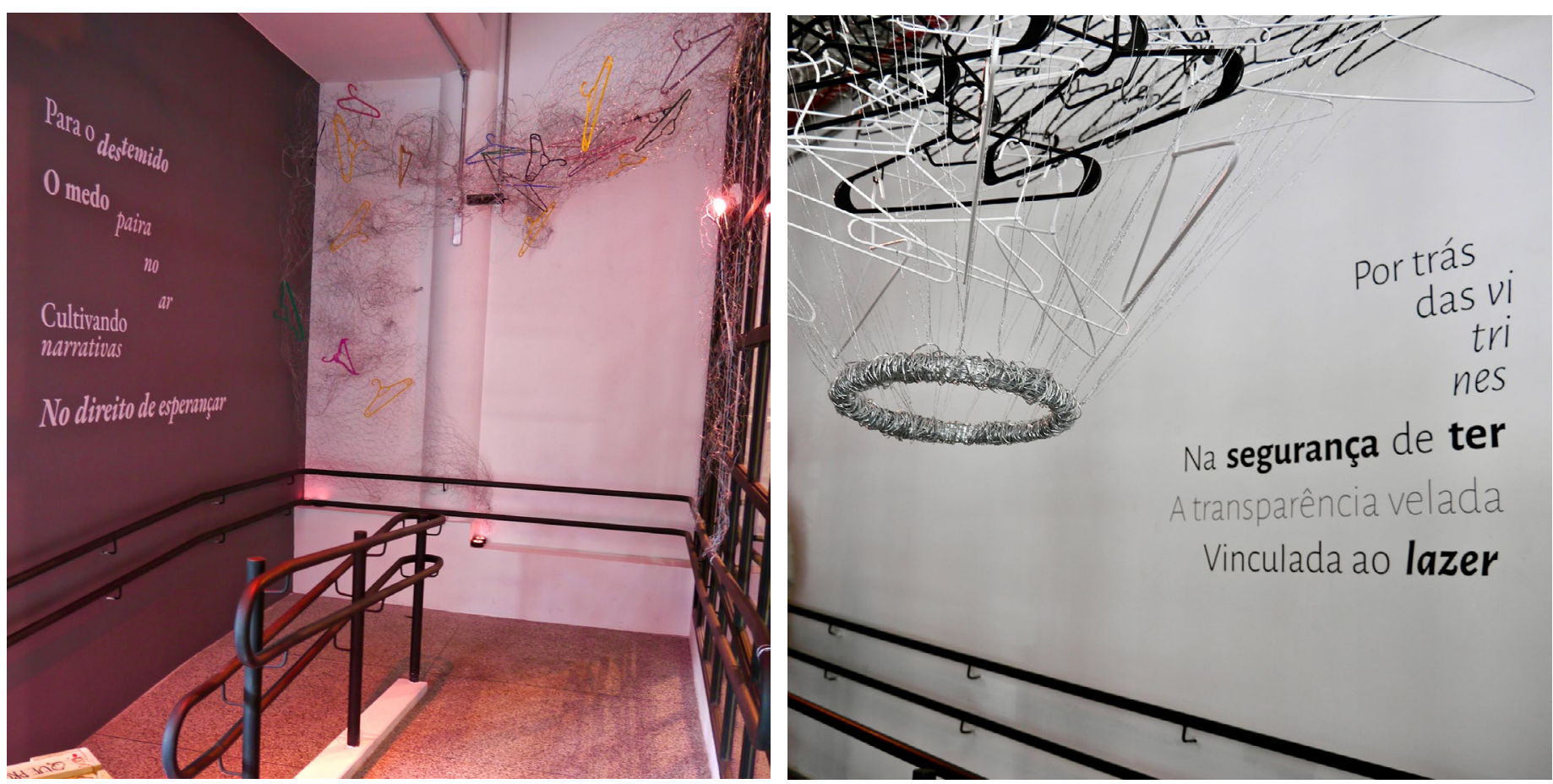

Fig 3. Exposição realizada no Espaço Cultural Renato Russo - 508 SUL representando o CONIC e o Conjunto Nacional. 
A experiência anterior também proporcionou a realização de uma instalação artística em que os participantes da pesquisa construíram para que outras pessoas e habitantes da cidade pudessem experimentar as condições encontradas nos lugares estudados (Figura 3).

Compreendemos que a importância dos dados coletados, para além da experiência estética que eles podem proporcionar, e dos estudos a partir da metodologia empregada, possibilitam diversas formas de compreender, construir e reconstruir o espaço urbano a partir da sua teia social. Os dados brutos, análises, documentos e informações abertas sobre a cidade tem o objetivo de compartilhamento entre pesquisadores para novas e outras pesquisas futuras, para a sociedade, no momento que ela constrói sua representação sem mediadores, quanto para tomadas de decisão sobre políticas públicas.

\section{Considerações finais e continuidade dos estudos}

Em resumo, a experiência deste projeto trata de abordar questões fundamentais sobre os pontos de partida e principais inflexões vividas no campo da cultura urbana pela mediação tecnológica, analisando os desafios e limites da introdução de novos suportes, canais e modelos de mediação para um exercício ativo da cidadania, como estão incidindo os processos intensivos de modernização do território e as políticas culturais no capital simbólico, e que lógicas de reprodução dos códigos autóctones de identidade e da memória e cultura locais têm lugar no espaço urbano hipermidiatizado.

Desta forma, nossa expectativa é colocar em comum, a partir da compreensão, interpretação e retratos, o exame das tendências e fundamentos para as análises das novas formas de organização social sobre a cidade, sobre Brasília Imaginada, analisando o papel da comunicação, do design, da arte e da cultura na configuração do espaço urbano desde as experiências concretas de articulação do capital simbólico em processos de modernização e transformação das cidades, a partir do imaginário de seus cidadãos por meio de exposições, trabalhos coletivos junto à cidadania $\mathrm{e}$ livros que comuniquem a experiências e os dados levantados. Compreende-se que o desenvolvimento do projeto possibilitará a geração da "Brasília Imaginada" por seus cidadãos, compreendendo múltiplas visões e informações a partir de suas experiências, sensibilidades e histórias de vida. Espera-se ainda a possibilidade de inter-relacionar as experiências culturais do espaço urbano que impulsionem novas formas de práticas cidadãs que vinculem territórios periféricos e centrais criando possibilidades de estreitamento dos laços que unem a cidadania. Além disto, busca-se a criação de uma base de dados para compartilhar os conhecimentos sobre indicadores, variáveis e tipos de processos urbanos que hoje incidem na abertura de dinâmicas de desenvolvimento local em Brasília. Esperamos com isso, que o projeto possa alcançar novos olhares e que seja compartilhado com outras cidades e países. 


\section{Referências}

AGAMBEN, Giorgio. Meios sem fim: notas sobre a política. Belo Horizonte: Autêntica, 2015. ESCODA, Ferran. Barcelona imaginada. Barcelona: Convenio Andres Bello, 2004.

LEFEBVRE, Henri. $O$ direito à cidade. Lisboa: Estúdio, 2012.

LYNCH, Kevin. A imagem da cidade. São Paulo: Martins Fontes, 1995.

LOTMAN, I. La semiosfera. V.1. Ed. Desidério Navarro. Madrid: Cátedra, 1996.

RISLER, Julia e ARES, Paulo. Manual de mapeo colectivo: recursos cartográficos críticos para procesos territoriales de creación colaborativa. Buenos Aires, 2013.

SANTOS, Milton. A natureza do espaço: técnica e tempo, razão e emoção. São Paulo: EDUSP, 2002.

SANTOS, Milton. Espaço e método. 5 ed. São Paulo: Edusp, 1985.

SANTOS, Milton. 0 espaço do cidadão. São Paulo: Nobel, 1998.

SILVA, Armando. Imaginários urbanos. São Paulo: Perspectiva, 2001. 